\title{
Anemia: Increasing prevalence in general population: why?
}

\author{
Rabindran $^{1}$, Gedam DS ${ }^{2}$ \\ ${ }^{1}$ Dr. Rabindran, Consultant Neonatologist, Billroth Hospital, Chennai, ${ }^{2}$ Dr D Sharad Gedam, Professor of Pediatrics, L N \\ Medical college, Bhopal, MP, India
}

Address for correspondence: Dr Rabindran, E mail: rabindranindia@yahoo.co.in

\begin{abstract}
In India, various surveys showed that over $70 \%$ of preschool children, pregnant women and adolescent girls are anaemic. Inspite of various government run nutritional supplements programe we are having very high prevalence of Anemia.
\end{abstract}

Keywords: Anemia, Children, Prevalence, Pregnant women

\begin{abstract}
Anemia affects approximately 2 billion people worldwide and remains a public health challenge [1]. Despite anapparent decline in global prevalence of anemia(from $40.2 \%$ in 1990 to $32.9 \%$ in 2010 ) owing to better nutrition andiron-fortified foods, itremains responsible for a significant burden, with a global increase in Years lived with disability (YLD) from 65.5 million to 68.4 million over the 20 -year period. By comparison, this is greater than the burden associated with major depression (63.2 million YLDs), chronic respiratory diseases (49.3 million YLDs) and general injuries (47.2 million YLDs).According to WHO, the prevalence of anemia is $48 \%$ in preschool-age children ( $<5$ years of age), $25 \%$ in school-age children ( 5 to 14 years), $13 \%$ in males (15 to 59 years), $42 \%$ in pregnant females, $30 \%$ in women of reproductive age (15 to 49 years), and $24 \%$ in the elderly (> 60 years) [2]. However in India, NNMB, DLHS and ICMR surveys showed that over $70 \%$ of preschool children ,pregnant women and adolescent girls were anaemic $[3,4,5]$.
\end{abstract}

Major causes of increasing prevalence of anemia are insufficient or abnormal red blood cell production (poor dietary intake and/or absorption of iron and other micronutrients; infectious diseases; increased requirements due to disease and growth), Excessive red blood cell destruction (malaria), Excessive red blood cell loss (helminths, bacterial or viral infections that cause blood loss; reproductive-related losses), deficiencies of essential nutrients or increased requirements including those seen in pregnancy.Unclean fuel use, poor toilet facilities, staying in non-concrete house, exposure to smoking, low body mass index, lower mean blood pressure, diabetes, respiratory and renal insufficiency and cancer also are found to be significantly associated with anemia, which explains the recent increasing prevalence of anemia.

With the rapid increase in the older population, the high prevalence of anemia seems to be an emerging problem of the older age group. Current opinion favors that anemia in elderly is due to a diminished erythropoietic reserve with aging, abnormal cytokine modulation of erythropoiesis, serum creatinine and albumin abnormalities, lower baseline erythroid 2,3diphosphoglycerate levels \& higher red blood cell mean corpuscular volume. Certainly, specific diseases causing Anemia of Chronic disease, namely cancer, infection and chronic inflammatory diseases such as rheumatoid arthritis are more common in the elderly.

Factors associated with childhood anemia include nutritional (folate, vitamin A and vitamin B12), infectious and parasitic diseases (diarrhea, malaria, geohelminthosis), glucose-6-phosphate dehydrogenase deficiency\& genetically derived hemoglobinopathies.In the NFHS-3, only $14.6 \%$ of children aged 6-35 months consumed food rich in iron in the previous 24 hours of the survey [6].In India, at age 6-8 months only $45 \%$ of children receiving breastfeeding are given solid or semisolid food [6]. Moreover, only $10 \%$ of breastfeeding children and $20 \%$ of nonbreastfeeding children aged 6-35 months eat meat, fish, or eggs [6], which are rich in haem iron. These cause the increasing prevalence of anemia among our children. 
Among women of reproductive age group prevalence of anemia was found to be $92.5 \%$ \& $96.8 \%$ in studies by Kaur et al.,[7] \& Mishra $\mathrm{P}$ et al.,[8] respectively. In India, only $28 \%$ of women consume meat, fish or eggs on a weekly basis [6] and the iron bioavailability of the vegetarian diet is poor. Predisposing factors for anemia among women include grand multiparity, low socioeconomic status, maternal infection, late prenatal care, HIV infection and inadequate spacing of children .The pathogenesis of anemia in diabetes includes diabetic nephropathy, chronic inflammation, and functional erythropoietin deficiency. The pathogenesis is systemic inflammatory response in chronic obstructive pulmonary disease and decreased renal synthesis of erythropoietin in chronic kidney disease.

In India, the prevalence of anaemia in general population is high because of ( $i$ ) low dietary intake, poor iron $(<20 \mathrm{mg} /$ day) and folic acid intake $(<70$ $\mathrm{mg} /$ day); (ii) poor bioavailability of iron (3-4\% only) in phytate and fibre-rich Indian diet; and (iii) chronic blood loss due to infection such as malaria and hookworm infestations [5].

Interventions that will decrease Anemia are Improving intake of iron, Supplementation, Food fortification ,Food processing; Preventing \& Controlling Malaria , Clean water and sanitation access,Preventing \& Controlling Hookworm \&Schistosomiasis.Considering the rapid increase in the older population, an intervention topreventanemia and iron depletion in elderly is imperative.Childhood Anemiacan be prevented with promotion of food security, improved living conditions and sanitation, and the treatment and prevention of parasitic diseases such as malaria and intestinal parasites.

In a study published by Saha $\mathbf{J}$ et al in this issue prevalence of Iron deficiency (ID) and Iron deficiency anemia (IDA) were $55 \%$, \& $11 \%$ respectively among adolescent girls. In this study sample size was very small [9].

\section{References}

1. Mlean E, Conges M, Egli I, Wojdyla D, Debendit B. Worldwide prevalence of anemia: WHO vitamin and mineral nutrition information system:1993 -2005: Public Health Nutr.2008:12(14): 444- 54.

2. de Benoist B, McLean E, Egli I, Cogswell M, eds. Worldwide prevalence of anaemia 1993-2005. WHO global database on anaemia. Geneva, Switzerland: WHO Press, 2008:1-40.

3. IIPS. National Family Health Survey 2005-06 (NFHS-3): Available from: http://mohfw.nic.in/nfhsfactsheet.htm; accessed on September 24, 2008.

4. DLHS on RCH. Nutritional status of children and prevalence of anaemia among children, adolescent grils and pregnant women 2002-2004. Available from: http://www.rchindia.org/ nr_india.htm 2006, accessed on September 24, 2008.

5. Toteja GS, Singh P. Micronutrient profile of Indian population. New Delhi: Indian Council of Medical Research; 2004.

6. F. Arnold, S. Parasuraman, P. Arokiasamy, and M. Kothari, "Nutrition in India," inNationalFamilyHealth Survey (NFHS-3) India 2005-06, 2009, http://www.rchiips.org/nfhs/nutrition report for website 18sep09.pdf

7. Kaur, M. and K. Singh (2001). Effect of Health Education on Knowledge, Attitude and Practices About Anaemia Among Rural Women in Chandigarh. Indian Journal of Community Medicine, 26(3): 128-128.

8. Mishra P, Ahluwalia SK, Garg PK, Kar R, Panda GK . The prevalence of Anemia among reproductive age group (15-45 years) women in a PHC of rural field area of MM Medical College, Ambala, India. J Women's Health Care. 2012;1(3): 1-3.

\section{How to cite this article?}

Rabindran, Gedam DS. Anemia: Increasing prevalence in general population: why ?. Int J Med Res Rev 2015;3(7):673674. doi: 10.17511/ijmrr.2015.i7.144. 